\title{
CONFLICTO Y MULTICULTURALIDAD DE LOS PUEBLOS INDÍGENAS: ANÁLISIS DEL CASO DE LA COMUNIDAD NATIVA TRES ISLAS
}

\author{
CONFLICT AND MULTICULTURAL OF INDIGENOUS PEOPLES: \\ THE CASE OF THE NATIVE COMMUNITY TRES ISLAS
}

\author{
JORGE ANTONIO GONZÁLES MIRANDA
}

Universidad Norbert Wiener

\section{RESUMEN}

La presente investigación analiza el caso de la comunidad nativa Tres Islas, ubicada en la región de Madre de Dios, Perú. La comunidad decide proteger su territorio del daño ambiental, ocasionado por la extracción de recursos que realizan las empresas Los Mineros SAC y Los Pioneros SCRL. Las empresas elevaron su reclamo a las autoridades judiciales alegando el derecho al libre tránsito. El Poder Judicial, en primera y en segunda instancia, les dio la razón, ordenando el desahucio de la caseta de control de tránsito que había construido la comunidad para proteger sus tierras; por tanto, la comunidad decide llevar el litigio al Tribunal Constitucional.

La finalidad del trabajo consiste en analizar los hechos y derechos conculcados a la comunidad nativa Tres Islas desde la mirada de los derechos humanos, la problemática de la multiculturalidad y los conceptos de educación intercultural y cultura de paz. Estos ejes permitirán traducir una realidad latente donde se evidencia la exclusión de los indígenas de los ámbitos sociojurídicos; lamentablemente, solo se respetan los parámetros culturales impuestos por Occidente, desconociendo las otras cosmovisiones.

Palabras clave: comunidad nativa, conflicto, cultura de paz, derechos humanos, multiculturalidad, interculturalidad.

\section{ABSTRACT}

This research analyzes the case of the Native Community named Tres Islas that is located in the Madre de Dios Region of Peru. The Community decides to protect its territory from environmental damage as a consequence of the indiscriminate extraction of resources by companies "Los Mineros SAC" and "The Pioneers SCRL". Companies raised their claim to the judicial authorities claiming the right to free movement. The judiciary, in first and second instance, gave them reason ordering the eviction of the traffic control booth that the Community had built whit the objective to protect their lands. The Community decides to take the case to the Constitutional Court. 
The purpose of the work is to analyze the facts and violated rights to the Native Community Tres Islas from the perspective of human rights and the issue of Multiculturalism and concepts of Intercultural Education and Culture of Peace. These axes will allow translating a latent reality where exclusion of native people from the socio-legal sphere evidenced area legal; unfortunately only respected cultural parameters imposed by the west ignoring the other worldviews.

Key words: Native Community, Conflict, Culture of Peace, Human Rights, Multiculturalism, Interculturalism

\section{INTRODUCCIÓN}

La comunidad nativa Tres Islas está ubicada en la región Madre de Dios, Perú, y su territorio cuenta con una amplia riqueza en recursos naturales y minerales.

Según el Instituto Internacional de Derecho y Sociedad, la comunidad construyó un camino para conectarse con la carretera principal (Interoceánica) y de esta manera beneficiarse de las oportunidades de desarrollo establecidas por esta interconexión entre el Perú, la región centro occidental del Brasil y el norte de Bolivia. Sin embargo -y aprovechando la coyuntura- dos empresas de transportes se valieron de dicho camino para ingresar al territorio de Tres Islas y extraer -ilegalmente- madera y minerales, causando impactos negativos a la comunidad y al medio ambiente (2014, párr. 3).

Es entonces cuando la comunidad decide proteger su territorio del daño ambiental, producto de la indiscriminada extracción de recursos, y construye una caseta de control de tránsito apelando a su derecho a la autodeterminación. Esta acción originó el conflicto entre la comunidad nativa Tres Islas con las empresas Los Mineros SAC y Los Pioneros SCRL, que elevaron su reclamo a las autoridades judiciales alegando su derecho al libre tránsito. El Poder Judicial, en primera y en segunda instancia, avaló el petitorio de las empresas, ordenando el desahucio de la caseta de control de tránsito. Por su parte, la comunidad presentó recursos legales para salvaguardar sus derechos (Instituto Internacional de Derecho y Sociedad 2014, párr. 5).

El conflicto/litigio llegó al Tribunal Constitucional, que emitió la primera sentencia en materia de reconocimiento de derechos de los indígenas, enfatizando la capacidad que tienen los pueblos originarios para autodeterminarse en aspectos administrativos, económicos y normativos. El Tribunal se ampara en lo estipulado por la Constitución Política del Perú sobre el derecho a la autodeterminación, que a su vez es ratificado por el Convenio 169 de la Organización Internacional del Trabajo (OIT).

Finalmente, el presente trabajo no pretende agotar la temática que acarrean los conflictos de multiculturalidad. El objetivo de la investigación es analizar los hechos y derechos conculcados a la comunidad nativa Tres Islas desde la mirada de los derechos humanos, la multiculturalidad y los conceptos de educación intercultural y cultura de paz. 


\section{PROBLEMA}

\section{Sobre el concepto de conflicto}

El conflicto es innato al ser humano y no va a desaparecer, de ahí su riqueza conceptual para estudio. Así lo sostiene Rodríguez Soto, que señala que "los conflictos son normales y naturales, forman parte de la condición humana y no hay que asustarse por ellos" (2012: 12). No obstante, no quiere decir que no pueda evitarse, todo lo contrario. Precisamente, la cultura es la que determinará los niveles de conflicto $o$ violencia que pueden generarse en una sociedad y cómo esta puede tratarse y, en algunos casos, cohonestar o desaparecer.

El origen etimológico de la palabra 'conflicto' viene del latín conflictus, que significa, 'chocar unos con otros y otras' (París y Martínez 2004: 88-89).Vicenç Fisas sostiene que el conflicto es una incompatibilidad o un antagonismo entre dos o más partes que expresa una insatisfacción sobre un determinado tema; es un proceso interactivo, de construcción social, con posibilidad de ser transformado y superado por las mismas partes o por un tercero (1998: 29-30).

Lederach define el conflicto como "una lucha expresada entre, al menos, dos personas o grupos interdependientes, que persiguen objetivos incompatibles, recompensas escasas, e interferencias del otro en realizar sus metas" (1984: 44). Asimismo, Caireta y Barbeito definen el conflicto "como aquella situación de disputa o divergencia en que hay una contraposición de intereses (tangibles), necesidades y/o valores en pugna entre dos o más partes" (2005: 23). En esa misma línea, Rodríguez sostiene que "un conflicto se da cuando dos partes tienen fines o comportamientos incompatibles" (2012: 16).
Este antagonismo, rivalidad, disputa o divergencia entre las partes, conforme se define en los distintos conceptos de conflicto expuestos, tiene su origen en la percepción de discutir para la obtención de las necesidades sociales que se logra a lo largo de la vida (Lederach 1984: 44). En la búsqueda nace el conflicto.

Todos los seres humanos quieren algo para satisfacer sus expectativas sociales. El conflicto se presenta cuando no se puede conseguir o cuando, específicamente, pertenece a un tercero (percepción de rivalidad). Por ejemplo, en el caso de Tres Islas, lo que quieren los transportistas es explotar los recursos naturales de la comunidad, mientras que esta busca defender su territorio.

En algunos casos se negociarán las necesidades con la otra parte para evitar el conflicto, pero no siempre lo que se anhela tendrá la posibilidad de ser adquirido, ya sea porque no está al alcance (ni física, económica, social o jurídicamente) o, en términos más complejos, porque la otra parte no está dispuesta a renunciar y ceder sus anhelos y deseos en favor de las comunidades.

\section{Los conflictos sociales y la problemática del reconocimiento sociojurídico de los indígenas}

Lo que ocurrió entre la comunidad y los transportistas fue un conflicto sociojurídico donde se excluyen las razones de defensa del territorio y se rechaza, en las dos primeras instancias, la cosmovisión de la comunidad. Frente a esta realidad de aberraciones sociojurídicas, para entenderla en un plano mayor es necesario remontarse al pasado e intentar mostrar cuándo nace el afán por desconocer la cultura y derechos de los indígenas. 
La historia dice con exactitud cuándo se dio inicio al desconocimiento y vulneración de los derechos de los pueblos indígenas. La Corona espańola, la de los reyes católicos de Aragón y Castilla, Fernando e Isabela -con fines claramente expansionistas-, logró financiar expediciones con la única intención de encontrar la tierra prometida y extender su poderío hacia un lugar desconocido y extremadamente rico en recursos naturales y minerales. $\mathrm{La}$ Conquista de América marca el punto de partida para analizar la vulneración de los derechos de los indígenas, de sus tradiciones y costumbres.

Los reyes de España hallaron un nuevo continente; sin embargo, existía un inconveniente, estos terrenos no estaban desiertos: se encontraban ocupados por poblaciones indígenas, lo que no les permitía simplemente disponer de toda la abundancia contenida en aquella exótica región.

Los indígenas eran los poseedores y propietarios del territorio vasto en riquezas (Hernández 1998: 73). La Corona, frente a este escenario, aplica la política de colonizar a los indios sometiéndolos al pensamiento occidental, a sus usos y nuevas costumbres. Los conquistadores entendieron que debían doblegarse las tradiciones y costumbres de los indígenas (Bauman 2003: 111); por ende, al quebrar su identidad cultural (Taylor 1993: 44), podrían disponer de las riquezas de estos. Pero este objetivo solo podría lograrse a través del uso de la fuerza o violencia.

Lamentablemente, el proceso de colonización (sometimiento cultural) fue duro para los indígenas. No fueron respetados en sus costumbres, ni tradiciones, ni mucho menos contaban con derechos; se les desconoció hasta su calidad de humanos, pasando a ser seres inferiores que le debían pleitesía a los señores de la Corona. Se sometió así a todo un pueblo a través del uso de la fuerza y de las armas; jamás se permitió el diálogo entre culturas.

"[Pero] las armas no fueron el único recurso usado por la monarquía española sino también lo fue el discurso de la religión católica” (Hernández 1998: 111), con la que justificaban -en aras de enseñar a los indígenas salvajes una nueva culturasu intervención en el nuevo continente; así facilitaban la dominación de tierras y recursos, pues se adoctrinaba en la "nueva fe", la misma que estipulaba ceder las propiedades a la monarquía. Es así que, haciendo uso de la fuerza física (armas) y psicológica (religión) empieza la dominación, vulneración y casi exterminio de la raza indígena.

La Corona española tuvo que actuar con violencia porque sus intereses eran obtener las riquezas naturales y minerales que habían encontrado y el plan para lograr dicho objetivo, consistió en quebrar la identidad del pueblo indígena (Martínez de Bringas 2003: 11-13) pues de esta manera - sin identidad - estos no iban a poner mayor resistencia y se perderían en su propia existencia: el exterminio fue la primera decisión política. No obstante, la Corona se dio cuenta de que con el exterminio no iba a lograr nada más que un genocidio de magnas dimensiones. La estrategia cambia y se adopta un nuevo discurso: hacer que los indios se "sientan protegidos" por sus conquistadores y, de esa manera, respeten a la Corona, pues se les iba a otorgar un "Estado de Bienestar" (Vidal-Beyneto 2004: 277). De este (aparente) estado de bienestar nace el derecho indiano.

El derecho indiano o derecho de indias, como también se le conoce, no soluciona- 
ba el problema para los indígenas. Este derecho no reconoce (o reconocía en partes porque siempre las decisiones trascendentales las tomaban los conquistadores) las tradiciones y costumbres ancestrales de los pueblos indígenas $\mathrm{u}$ originarios; por tanto, lo único que se logró fue terminar de sepultar los "valores" de los indígenas, sometiéndolos a una esclavitud encubierta gracias a un manto de hipocresía jurídica. Este derecho indiano realmente tenía por finalidad separar a los civilizados (españoles) de los bárbaros (indígenas), realizándose una clasificación social (exclusión) y de división de trabajo que establecía la etiqueta de patrón/esclavo a través de la 'mita' y la 'encomienda' (Martínez de Bringas 2003: 16), forma de trabajo que confirman la estrategia perversa al colocar a los indígenas como simples peones de un ajedrez expansionista (citado en Berraondo, Mikel 2006: 537-567). Finalmente, se dejó de exterminar a los indígenas, pero se pasó a esclavizarlos. Ya no se mataba, siempre y cuando se pagasen los tributos impuestos por la Corona.

Tal vez no sean suficientes estas líneas para explicar todo el proceso colonizador; aunque la brevedad con que se narran los hechos resulta práctica para poner en la palestra el punto de partida de cuándo nace la vulneración de los derechos de los indígenas y la exclusión social a la que fueron sometidos. Es importante explicar esta parte de la historia para entender que desde la conquista la identidad del pueblo indígena $\mathrm{u}$ originario fue intimidada y quebrada por los conquistadores. Es en este momento histórico cuando se produce el quiebre en la identidad indígena, cuando se logra la separación (exclusión) sociojurídica.

Conflicto, multiculturalidad y derecho de los indígenas: migrando hacia la interculturalidad
Se puede apreciar que el desconocimiento y la vulneración, no solo de derechos, sino también de la identidad y cultura indígena, nace durante la conquista europea en Latinoamérica. Hoy se sigue aplicando una mirada eurocéntrica que impide aceptar otras cosmovisiones. Desde este eurocentrismo, se ha creado una sociedad de estructuras administrativas, económicas y judiciales que responde a un monoculturalismo inquebrantable que trastoca la multiculturalidad.

En las siguientes líneas se propone analizar los conceptos de monismo cultural y de multiculturalidad y sus formas de gestionar la diversidad. La finalidad, en primer lugar, es hacer una diferenciación dogmática de ambos conceptos $\mathrm{y}$, a partir de ahí, observar -a la luz del caso Tres Islas- cuál de estos modelos viene aplicándose en el Perú (o no) y a cuál de ellos se debe aspirar en este caso. Asimismo, determinados los modelos conceptuales, se analizará la tratativa de los derechos de los indígenas.

\section{Multiculturalidad y derechos}

La multiculturalidad es una realidad social. Quienes consideraban que podía hablarse de parámetros culturales homogeneizados para el desarrollo del hombre en sociedad estaban equivocados (García Canclini 2004: 56-82). Un Estado que se considere superior culturalmente no podrá lidiar con la inminente diversidad cultural. Conforme lo sostiene Kymlicka, al decir que los Estados modernos no deben considerarse poderíos culturales, pues no hay cultura superior; el reflejo de dicha premisa que niega la supremacía reposa sobre el concepto de multiculturalidad (1996: 25).

La multiculturalidad per se se enfrenta a los temas de convivencia en la diversidad de cosmovisiones. El concepto entiende 
la existencia de formas de vida distintas, producto de la diversidad cultural, que repercute en los aspectos administrativos, económicos y hasta en la forma como se administrará la justicia (derecho a la autodeterminación) dentro de un Estado. La multiculturalidad no condice con las estructuras impuestas por el "modelo único" de carácter occidental o denominado monismo cultural (Díaz-Polanco 2005: 3).

En este caso se reconoce al Perú dogmática y jurídicamente, conforme lo establece la Constitución Política en sus artículos 2, 17, 48, 89, 139 y 149: un Estado con diversidad cultural; sin embargo, este enunciado resulta insuficiente, pues casos como el de Tres Islas demuestran que el camino es errado.

Para una correcta aplicación y reconocimiento del concepto de multiculturalidad, en primer lugar se debe entender al Perú como nación que comparte, dentro del mismo territorio, una cultura diferenciada. Así lo expresa Kymlicka al proponer una nación de Estados multinacionales, es decir, donde un país contiene más de una nación, donde las culturas más pequeñas conforman las minorías nacionales (1996: 26). Bajo esta visión, el concepto de pueblo indígena, como unidad en cuanto a la funcionalidad de sus políticas públicas relacionadas con la diversidad cultural, tendrá sentido. No obstante, se aplica todo lo contrario, es decir, la etnofagia cultural donde impera una sola idea: el monismo cultural (Díaz-Polanco 2005: 3).

Analizando el monismo cultural que se impone en el Perú -en términos de funcionalidad de sus instituciones administrativas, económicas y judiciales- aún reconoce como única y exclusiva fuente de referencia los parámetros impuestos por la cultura occidental. De continuar con esta segregación sociojurídica y desconociendo la diversidad cultural, es improbable lograr inclusión social, propiciándose por consiguiente actos de injusticia y de marginación social.

Para quebrar los esquemas del monismo se propone la aplicación de una visión de la multiculturalidad en su fase intercultural. Este concepto busca alcanzar el reconocimiento sociojurídico de aquellas 'formas de vida' o 'cosmovisiones' (Kincheloe y Steinberg 1999: 27) propias de la diversidad cultural. La interculturalidad es el modelo que debe perseguir todo Estado democrático que pretenda oír las costumbres y/o tradiciones que confluyen en su territorio.

La interculturalidad permitirá un reconocimiento de iure en la igualdad y permitirá una verdadera convivencia en la diversidad. No hay culturas superiores ni inferiores; existen diferencias en cuanto a las formas de concebir el mundo, lo que enriquece el intercambio social. Por tanto, los pueblos indígenas son distintos, pero no desiguales sociojurídicamente.

El concepto de interculturalidad se fundamenta en la interpretación, tolerancia e igualdad por la diversidad cultural y en el respeto y valoración por la naturaleza humana, finalidades que se logran a través de la búsqueda de un lenguaje común dentro de la misma diversidad, para lograr una convivencia armónica.

Finalmente, se considera que instaurando políticas gubernamentales (en lo administrativo, económico y normativo), reconociendo la diversidad cultural y creando instituciones en el sentido que propone la interculturalidad, se podrá lograr el reconocimiento de los derechos de los indígenas y su identidad cultural. El 
respeto por esta identidad cultural se dará a través del reconocimiento por la diferencia, haciendo uso de la tolerancia como técnica para el diálogo intercultural. Asimismo, es la aprehensión (en el sentido de aprender a interpretar) y la valoración de las distintas cosmovisiones lo que determina la viabilidad de dicho diálogo.

\section{Derechos afectados a la comunidad y un nuevo horizonte a partir de la sentencia del tribunal constitucional}

Este conflicto inicia cuando la comunidad nativa decide construir la caseta de control de tránsito para impedir la explotación de los recursos naturales y minerales en su territorio.

A continuación se analizarán las etapas del conflicto Tres Islas a través de los conceptos de la cultura de paz. Posteriormente se responderá si la acción de construir la caseta era justificada o no, y si estaba amparada por el sistema jurídico peruano.

Etapas del conflicto y agentes en el caso

\section{Tres Islas}

De acuerdo con los conceptos de la cultura de paz propuestos por Rodríguez Soto, el conflicto pasa por distintas etapas (2012: 17 y ss.). Tomando a la comunidad Tres Islas-objeto de estudio-, se mencionan las siguientes:

- Acontecimiento precipitador. La comunidad nativa Tres Islas observa cómo los transportistas informales explotan sus recursos naturales.

- La gente se agrupa para discutir el tema de disputa. La comunidad estaba agrupada, organizada (social y jurídicamente) y unida bajo la dirección de la entonces presidenta Juana Payaba.
- Se radicalizan las posiciones. Los transportistas ilegales pretendían ingresar indefectiblemente a los terrenos de la comunidad. Recurrieron a las autoridades locales para conseguir un permiso de tránsito que les permitiera ingresar al territorio comunal. La comunidad construye una caseta de control buscando hacer respetar sus derechos (autodeterminación).

- Paralización de la comunicación. Los transportistas ilegales nunca decidieron dialogar con los miembros de la comunidad.

- El conflicto sale al exterior. Las autoridades judiciales autorizan el desahucio de la caseta de control de tránsito que habían construido los miembros de la comunidad para salvaguardar su territorio.

- La crisis. Se presentaron actos beligerantes (violentos) entre los miembros de la comunidad y la policía, quien realizó el desahucio de la caseta por orden judicial a favor de los transportistas.

En cuanto a los agentes que intervienen en el conflicto, conforme lo menciona Fisas, se debe analizar cinco aspectos necesarios: "los actores involucrados, el litigio, la estructura de oportunidad, la interacción y la dinámica del conflicto" (1998: 31). Aplicando estos aspectos al caso Tres Islas, se determina lo siguiente:

- Los actores. Son la comunidad nativa Tres Islas, el Estado (representado por sus autoridades judiciales) y los particulares (las empresas de transporte).

- Del litigio. La pretensión de la comunidad nativa era el reconocimiento a la autodeterminación administrativa y normativa de la que gozan de acuerdo con la Constitución y el Tratado 169 OIT. La 
pretensión de los transportistas (mineros) informales era cruzar por el territorio que pertenecía a la comunidad para explotar los recursos naturales, basándose en el derecho constitucional al libre tránsito.

- De las estructuras de oportunidad. Se considera que los transportistas contaban con el apoyo del alcalde de la ciudad; por tanto, se manifiesta la relación de poder a través de la "autorización" que la autoridad edil les brindó para transitar por territorios de la comunidad.

- Sobre el liderazgo y estrategias. En confrontaciones, los líderes buscan enfrentamientos armados. En el caso de Tres Islas, la lideresa Juana Payaba se mantuvo firme en la lucha por los derechos de la comunidad, sin disturbios y sin hacer uso de la violencia física contra los transportistas informales. Siempre recurrió a una postura de diálogo y a las instancias judiciales para reclamar el respeto a sus derechos. La presidenta de la comunidad nativa Tres Islas hablaba en términos de cultura de paz.

\section{La sentencia del tribunal constitucional}

La sentencia marca un hito respecto a los derechos de los indígenas y la pauta constitucional de horizonte multicultural. No podía el Tribunal Constitucional fallar de otra manera, pues hubiera desconocido toda una cosmovisión de tiempos ancestrales quebrantando, principalmente, el concepto de identidad indígena que hoy debe ser ensalzado por todos.

La sentencia en sus fundamentos, marca puntos importantes merecedores de enunciarlos:

1. Constitución, multiculturalismo y realidad social: La Constitución de 1993 ha reconocido a la persona humana como miembro de un Estado multicultural y poliétnico; de ahí que no se desconozca la existencia de pueblos y culturas originarias y ancestrales del Perú. Tal reconocimiento no es una mera declaración formal de principios, sino que implica un cambio relevante en la propia noción del Estado y la Sociedad (Tribunal Constitucional 2012: 9).

2. Se reconoce el respeto a la diversidad y el pluralismo cultural, lo que tendrá que efectuarse siempre dentro del marco del respeto a los derechos fundamentales, el diálogo intercultural, los principios constitucionales y los valores superiores que la Constitución incorpora, tales como la dignidad de la persona, los principios de soberanía del pueblo, el estado democrático de derecho y la forma republicana de gobierno. El artículo 2. ${ }^{\circ}$, inciso 19, de la Constitución sobre el derecho a la identidad étnica y cultural, y el artículo $48 .^{\circ}$ de la Constitución declaran que, además del castellano, también son idiomas oficiales el quechua, el aimara y las demás lenguas aborígenes en las zonas donde predominen. Por su parte, el artículo 89. ${ }^{\circ}$ de la Constitución reconoce la autonomía organizativa, económica y administrativa de las comunidades nativas, así como la libre disposición de sus tierras, las que no son materia de prescripción, reiterándose de igual forma la obligación del Estado de respetar su identidad cultural. A su vez, el artículo $149 .{ }^{\circ}$ permite que las comunidades nativas y campesinas puedan aplicar su derecho consuetudinario, ejercitando funciones jurisdiccionales dentro de su ámbito territorial, siempre que no vulneren derechos fundamentales (Tribunal Constitucional 2012: 10).

3. Garantía de la propiedad sobre la tierra de las comunidades nativas y campesinas: Se debe romper con la mirada civilista de la propiedad y hacerla desde una mirada multicultural. La Constitución, en sus artículos $88 .^{\circ}$ y $89 .^{\circ}$, hace referencia a la 
protección de las tierras de las comunidades campesinas y nativas sin recoger el concepto de 'territorio' de forma expresa. El Convenio 169 establece en su artículo $13 .^{\circ}$ que la utilización del término 'tierras' debe incluir el concepto de 'territorios' (OIT 2007: 28). La diferencia entre el concepto de tierra y territorio radica en que el primero se encuentra dentro de una dimensión civil o patrimonial, y el segundo tiene una vocación política de autogobierno y autonomía (Tribunal Constitucional 2012: 13).

4. Los artículos $3 .^{\circ}$ y $4 .^{\circ}$ de la Declaración de las Naciones Unidas Sobre Derecho de los Pueblos Indígenas sostiene que el reconocimiento de los pueblos indígenas, con sus costumbres propias, sus formas de creación del derecho y aplicación del mismo, traspasan la dimensión de una mera asociación civil; su visión se orienta sobre una dimensión política, establecida en última instancia en el derecho a la autodeterminación de los pueblos indígenas (2007: 5). El objetivo de la autodeterminación es el respeto de su autonomía para definir sus propios destinos, así como su idea y proyecto de desarrollo (Tribunal Constitucional 2012: 13).

5. El artículo $18 .^{\circ}$ del Convenio 169 establece que "La ley deberá prever sanciones apropiadas contra toda intrusión no autorizada en las tierras de los pueblos interesados o todo uso no autorizado de las mismas por personas ajenas a ellos, y los gobiernos deberán tomar medidas para impedir tales infracciones" (OIT 2007: 33-34). En efecto, la Constitución establece una garantía expresa sobre la propiedad de la tierra en forma comunal o cualquier forma asociativa. Además, el artículo 89. ${ }^{\circ}$ señala que las comunidades campesinas y nativas deciden sobre el uso y la libre disposición de sus tierras, desprendiéndose de ello la facultad para decidir quiénes ingre- san o no a sus territorios. Las comunidades campesinas y nativas tienen el legítimo derecho de, en virtud del derecho a la propiedad, controlar intrusiones a su propiedad (Tribunal Constitucional 2012: 14).

6. Sobre la afectación de la autonomía comunal, señala el Tribunal Constitucional que en el presente caso se está ante una determinación no jurisdiccional de la comunidad nativa, ya que no se resolvió un conflicto interpersonal, sino que plasmó una medida sobre el "uso y la libre disposición de sus tierras" en virtud de la autonomía reconocida por el artículo $89 .^{\circ}$ de la Constitución.

7. El artículo 7. ${ }^{\circ}$ del Convenio 169 establece que "Los pueblos interesados deberán tener el derecho de decidir sus propias prioridades en lo que atañe al proceso de desarrollo, en la medida en que éste afecte sus vidas, creencias, instituciones y bienestar espiritual y a las tierras que ocupan o utilizan de alguna manera, y de controlar, en la medida de lo posible, su propio desarrollo económico, social y cultural". Ello puede verse materializado a través del ejercicio de su autonomía. El artículo 89. ${ }^{\circ}$ de la Constitución preceptúa que las comunidades nativas pueden disponer $y$ hacer uso de sus territorios. En tal sentido, al no haberse permitido ejercer su derecho a controlar el ingreso de terceros a su comunidad, se ha vulnerado el ámbito de autonomía de la comunidad nativa Tres Islas (Tribunal Constitucional 2012: 19-20).

8. La autonomía de las comunidades nativas y campesinas debe ser ejercida dentro del marco constitucional y legal, siempre que no se desnaturalice la esencia del derecho. En este caso, la construcción de la caseta y el cerco de madera fue una decisión legítima tomada en virtud de su autonomía comunal, reconocida en el artículo 
89. de la Constitución. En ese sentido, al ser tal medida el ejercicio de un derecho constitucionalmente protegido, no podrían generarse consecuencias lesivas a tal actividad (Tribunal Constitucional 2012: 20).

9. Se estima pertinente enfatizar que en virtud del Convenio 169 y la Ley 29785, el Estado está obligado a consultar previamente a los pueblos indígenas aquellos actos administrativos o legislativos que pudieran afectar directamente sobre las consecuencias del ejercicio de protección del territorio comunal y la autonomía comunal (Tribunal Constitucional 2012: 19).

\section{Cultura de paz y conflicto}

El concepto de cultura de paz aparece después de la II Guerra Mundial, pues los estados firmantes de los acuerdos de paz interiorizaron la necesidad de reconocer el concepto y aplicarlo como una herramienta que permita transformar a los seres humanos (Muñoz y Molina 2010: 45). Si bien la idea fue difundida por la Unesco desde 1989, el historiador Francisco Muńoz (Corporación Vida, Tierra e Diversidad: 2014) considera que el precursor fue el padre jesuita Felipe Mac Gregor, quien en 1986 ya hablaba de este término.

Felipe Mac Gregor vivió en el Perú y fue el pionero en la introducción del concepto de cultura de paz. Lamentablemente, a pesar de haber dejado la semilla, esta no germinó gracias a la desidia del Estado y las políticas pobres o desestimadas que, desde hace mucho, no abordan concienzudamente el tema de la paz y la resolución de conflictos. Se ha tomado algunas ideas del jesuita Mac Gregor de la entrevista que concedió a IDEELE, número $40 \mathrm{del}$ mes de agosto de 1992, donde hace referencia a la paz: "No creo que haya ningún pueblo que se haya construido sin enfrentar adversida- des. Las turbulencias son parte de la historia. Lo único que hay que saber hacer es saber aguardar" (Gutiérrez 2004: 48).

Tomando las palabras del padre Mc Gregor, efectivamente, es ineludible el conflicto porque es parte de la complejidad de los hombres; no obstante, ese "saber aguardar" encerraba la esperanza del creador del término 'cultura de paz'. Mc Gregor esperaba que el concepto fuera introducido a través de políticas públicas en favor de la sociedad; la difusión de esta teoría no haría más que lograr una mejor convivencia entre los hombres. Lamentablemente, no ha sucedido a cabalidad en el Perú.

Siguiendo la línea de Mc Gregor, para crear paz hay que pensar en términos de paz. La instauración de políticas públicas que discurran sobre una cultura de paz (hablando en términos doctrinarios) sería uno de los pasos para intentar alcanzar dicho estado. No obstante, la dación de políticas implica, para la sociedad en su conjunto, compromisos y renuncias a los egoísmos personales y culturales. En el Perú no existe un discurso por la paz (real) ni mucho menos el compromiso político (sostenible) para lograrlo; los gobiernos central, regional o local no cuentan con planes que permitan diseñar un camino hacia la cultura de paz, ahondando en los conflictos sociales (Rodríguez 2012: 47).

Para lograr este ideal, y vivir en una sociedad menos conflictiva, debe implementarse dos herramientas claves para alcanzar una solución pacífica, justa y equitativa: saber oír, o lo que se denomina 'escucha activa', y la capacidad de diálogo (Rodríguez 2012: 45).

Cuando se aplica la escucha activa se renuncia al egoísmo personal y cultural pues se habrá aprendido que existen otras for- 
mas de entender las expectativas sociales. La escucha activa es el abrirse a lo que las partes en conflicto puedan decir. No emitir juicios de valor antes de oír las posturas enfrentadas; siempre se dice que es más fácil hablar (porque el que habla detenta cierto poder) que saber oír (que no es simplemente una postura pasiva, sino todo lo contrario, activa, porque es un receptor al que le importa lo que dice su emisor).

Aquello que complementa la escucha activa es el hablar sobre el conflicto: 'capacidad de diálogo'. Los seres humanos, al ser racionales y poseedores de un discurso, necesitan aprender a transmitir sus necesidades, sus sentimientos. Si se intenta resolver un conflicto por el diálogo hay más posibilidades de éxito que hacerlo por el uso de la fuerza (Fisas 1998: 25; Rodríguez 2012: 15). En ese sentido, Arendt, haciendo referencia a los griegos, decía que: "vivir en la polis significaba que todo se decía por medio de la palabra y de la persuasión, y no con la fuerza y la violencia; no hacerlo constituía una forma pre política gobernando con poderes despóticos e indisputados" (Arendt 1993: 40).

Los que intervengan en el conflicto deben tener la capacidad de una escucha activa; asimismo, desarrollar el don del habla y la destreza para que se dialogue, con la finalidad de que las partes manifiesten sus posturas, intereses, necesidades y miedos (Rodríguez 2012: 21). Por ello, los elementos de la escucha activa y la capacidad de diálogo resultan herramientas trascendentales para afrontar cualquier tipo de conflicto.

Estas reflexiones permiten observar que las políticas socioeducativas poco o nada hacen por implantar y utilizar las herramientas que brinda la cultura de paz. No hay capacidad de escucha activa ni mucho menos de diálogo. No existe una política pública de paz que ayude a prevenir los conflictos sociales y mantener un estado de no violencia. Craso error.

\section{Educación e interculturalidad}

Nadie habla sobre temas de cultura de paz. Cuando se presentan los conflictos sociales no hay formas de afrontarlos de manera adecuada, pues no existen las herramientas para hacerlo (por ello el fracaso del diálogo entre culturas). Frente a esta problemática, se propone una respuesta coherente y realista que permita prevenir, afrontar y resolver los conflictos sociales. La respuesta está en la educación por la cultura de paz con visión intercultural. Es así que, además de seguirse una política multicultural, debe instaurarse una interculturalidad como respuesta al conflicto a través de la educación en sus distintos niveles.

Es innegable, el mundo de hoy es multicultural. Esta diversidad ha propiciado que las relaciones en una sociedad con cosmovisiones distintas generen conflictos (Colectivo Amani 2006: 16). Estos conflictos serán más o menos complejos de acuerdo con la cultura, pues esta es la que determina el grado de conflictividad de las relaciones sociales. Si una cultura no ha contemplado instaurar un lenguaje común -a pesar de la diversidad- de paz, será más difícil la convivencia. Por eso, la única forma de abordar la problemática de la multiculturalidad, y de la complejidad de las relaciones sociales inherentes a este concepto, es la implementación de políticas educativas de carácter intercultural.

La interculturalidad nace como concepto en 1975, en Francia, en el marco de proyectos educativos y sociales. Su finalidad es promover la igualdad de oportunidades de los miembros de la sociedad y lograr la convivencia, el respeto por la 
diversidad cultural y la creación de espacios de experiencias culturales entre los miembros de la sociedad multicultural (Essomba 2006: 44). Es así que la educación intercultural pasa a ser el instrumento de ejecución hacia la orientación multicultural, sin quedarse solo en el discurso dogmático inacabado.

Ha existido confusión e inclusión ambigua en el uso del término, pues existen estudios que hablan de educación multicultural e intercultural como sinónimos (Llevot 2006: 10). No obstante, se considera que más allá de la terminología, la educación, en términos generales, debe promover la modificación de las etiquetas sociales y de los prejuicios respecto a otras culturas, la valoración de otras tradiciones, la toma de conciencia de la diversidad y la no discriminación (Llevot 2006: 11).

Sin confundir la terminología y asumiendo la más difundida, la definición propuesta por Banks, que afirma tiene por finalidad: una educación sin cuestionamientos sobre las tradiciones culturales, la educación intercultural como reforzamiento de identidades, la enseñanza en las lenguas de origen, la lucha contra el racismo, la enseñanza de las tradiciones culturales, su valoración y el abandono de una cultura monista (Llevot 2006: 12-13).

La propuesta de Banks tiene como trasfondo valorar la diversidad cultural, por tanto, la educación debe ir en ese sentido. Precisamente, es con la implementación de una educación intercultural con la que se debe inculcar valores donde se entienda que existe la capacidad de actuar libremente, ya sea de forma individual o grupal, a pesar de las distintas culturas con las que se logre la convivencia pacífica. Esa valoración, conforme lo expresa Manuel Touriñán López, por la cultura distinta -pro- puesta de la interculturalidad- es un "compromiso ético fundado en la dignidad, la libertad, la igualdad, el desarrollo, la autonomía, la responsabilidad, la justicia, la diversidad y la cooperación: una alianza de civilizaciones" (citado en Instituto De Ciencia de Educación 2007: 64).

Por tanto, conforme señala Margarita Bartolomé, la funcionalidad del discurso intercultural se ve a través de la educación intercultural, la misma que remite a la dependencia, correspondencia y simetría de las culturas, por lo que supone una actitud receptiva frente a la diversidad, además de un compromiso ético. Asimismo, implica el diálogo y la comunicación entre los desiguales, ya sean grupos o personas (citado en Soriano 2011: 76-77).

Todas estas características propuestas por la educación intercultural tienen por finalidad eliminar la exclusión y conseguir una mayor cohesión social, conforme lo sostiene Escarbajal Frutos, al manifestar que la educación intercultural promueve la participación igualitaria de todos los miembros de la sociedad, sin discriminación; lo que significa crear conciencia en el respeto a todas las personas, independientemente de su procedencia cultural (2011: 125). Así también piensan Juan José Leiva Olivencia y María Teresa Rascón Gómez, al afirmar que "la educación intercultural promueve relaciones de igualdad y de mutuo enriquecimiento entre personas procedentes de culturas diferentes, mediante el aprendizaje de valores, habilidades, actitudes y conocimiento interculturales" (citado en Fundación SM: p. 93).

Por su parte, aporta a la definición Fidel Molina cuando manifiesta que "la educación intercultural ha de ser una educación en la solidaridad e igualdad (más allá de una tolerancia y una comprensión paterna- 
lista) en una sociedad plural. La educación intercultural aboga por el diálogo y la comunicación y, lejos de un posicionamiento estático multicultural, pretende proponer alternativas que ayuden en esta dinámica relación” (Molina 2008: 65).

Por tanto, el discurso que propone la educación intercultural es el motor de integración frente al tema de la convivencia en un estado de diversidad cultural. No obstante, estas políticas educativas no solo deberán mirarse desde la escuela (la cual será el principal pilar del cambio social), sino que deben exceder las estructuras administrativas, económicas y normativas. Si el Estado no es capaz de sostener un discurso basado en la educación intercultural, toda solución, frente a los conflictos de diversidad cultural, será inalcanzable.

\section{CONCLUSIONES}

Se han construido estructuras públicas que niegan reconocer y aplicar la visión multicultural que se quiere de país; esta infame realidad propicia conflictos en los ámbitos sociales, económicos y jurídicos, tal como ocurrió con la comunidad nativa Tres Islas.

La diversidad cultural sigue tratándose bajo los patrones del monismo cultural. Así lo demuestra el caso Tres Islas, donde se ha dado tratamiento desigual al momento de administrar justicia respecto a esta comunidad. Aquí se afectaron los derechos a la identidad cultural, al territorio y a la autodeterminación de los indígenas.

El caso Tres Islas reafirma que los pueblos indígenas tienen derechos constitucionales e internacionales que garantizan su libertad para actuar en ámbitos administrativos, económicos y normativos, ba- sándose en sus cosmovisiones (capacidad de autodeterminación); por ende, las sentencias, de primera y segunda instancia, del ente administrador de justicia quedan al margen de la ley. El derecho a la autodeterminación confirma la tolerancia por el otro al momento de determinar su vida en sociedad. Es la verdadera señal de un Estado donde impera la multiculturalidad. El derecho a la autodeterminación, reconocido en la sentencia del Tribunal Constitucional Peruano, sí reivindica la identidad cultural de la comunidad nativa.

Pero no solo debe reivindicarse el aspecto jurídico, como lo hizo el Tribunal, la solución de esta problemática está vinculada a la inserción del discurso por la igualdad a través de la propuesta de la cultura de paz. ¿Cómo se logrará? Implementando medios que permitan reforzar los lineamientos de la interculturalidad a través de la educación.

Finalmente, y conforme lo dijo José María Arguedas, se debe valorar la palabra 'indígena' dándole un sustento y contenido más justo. La palabra 'indio' quiere decir 'hombre con deberes y derechos y que ha dejado de ser hijo del conquistador'.

\section{BIBLIOGRAFÍA}

\section{ARENDT, Hannah}

1993 La Condición Humana. Barcelona, España. Ediciones Paidós Ibérica S.A.

BERRAONDO, Mikel

2006 Pueblos Indígenas y derechos humanos. Bilbao: Universidad de Deusto. Consulta: 26 de mayo 2016. Disponible en: <http://www.alertanet.org/ ryf-hitos-2006.pdf>. 
BAUMANN, Zygmunt

2003 Comunidad: En busca de seguridad en un mundo hostil. Madrtiuno de España Editores.

CAIRETA, Marina; BARBEITO Cécile

2005 Cuadernos De Educación Para La Paz Introducción de Conceptos: Paz, Violencia, Conflicto. Escola de Cultura de Pau. Universidad Autónoma de Barcelona. p. 23. Consulta: 22 de noviembre 2013. Disponible en: <http://escolapau.uab.cat/ $\mathrm{img} /$ programas/educacion/publicacion002e.pdfs.

CONGRESO DE LA REPÚBLICA DEL PERÚ

1993 Constitución Política del Perú

Consulta: 25 de mayo de 2016. Disponible en: <http://www4.congreso. gob.pe/ntley/Imagenes/Constitu/ Cons1993.pdf>.

2011 Ley 29785, Ley de la Consulta Previa a los pueblos indígenas u originarios, reconocidos en el Convenio 169 de la Organización Internacional del Trabajo. Publicada el 6 de setiembre de 2011. Consulta: 25 de mayo de 2016. Disponible en: <http://www2.congreso.gob. pe/sicr/cendocbib/con4_uibd.nsf/277ED2C085B6361805257A5C00725796/\$FILE/29785.pdf>.

\section{COLECTIVO AMANI}

2006 Educación intercultural: Análisis y resolución de conflictos. Madrid: Editorial Popular.

CORPORACIÓN VIDA, TIERRA Y DIVERSIDAD

2014 Cultura de paz, su historia y sus implicaciones. Publicado el 9 de octubre. Consulta: 26 de mayo de 2016. Disponible en: <https://tierraydiver- sidad.wordpress.com/2014/10/09/ cultura-de-paz-su-historia-y-sus-iplicaciones/>.

\section{DÍAZ-POLANCO, Héctor}

2005 Etnofagia y multiculturalismo.

Consulta: 24 de marzo de 2014. Disponible en: <http: //www.estudiosecologistas.org/docs/reflexion/ indigenas/etnofagia.pdf>.

DECLARACIÓN DE LAS NACIONES UNIDAS SOBRE LOS PUEBLOS INDÍGENAS

Consulta: 25 de mayo de 2016. Disponible en: <http://www.un.org/esa/ socdev/unpfii/documents/DRIPS_ es.pdfs.

ESSOMBA, Miquel Ángel

2006 Liderar escuelas interculturales $e$ inclusivas: Equipos directivos y profesorado ante la diversidad cultural y la inmigración. Barcelona: GRAÓ.

ESCARBAJAL FRUTOS, Andrés

2011 La formación del profesorado para una escuela intercultural, en Interculturalidad y Escuela: Perspectivas pedagógicas en la construcción comunitaria de la escuela intercultural. Barcelona: Ediciones Octaedro.

FISAS, Vicenç

1998 Cultura de paz y gestión de conflictos. Barcelona: Icaria-Ediciones Unesco.

\section{FUNDACIÓN SM}

2008 Diversidad, Convivencia y Educación desde el Conflicto. Julio Vera Vila (coord.) Universidad de Málaga, número 9.

\section{GARCÍA CANCLINI, Néstor}

2004 Diferentes, Desiguales y Desconectados. Barcelona: Gedisa S.A. 
GUTIÉRREZ, Gustavo

2004

La Cultura de Paz de Felipe Mc Gregor: Amigo y Maestro. Revista Institucional de Defensa Legal (IDEELE). Consulta: 26 de mayo de 2016. Disponible en: <http://www.revistaideele.com/ideele/content/n\%C3\%BAmero-166>.

HERNÁNDEZ MARTÍN, Ramón

1998 Francisco de Vitoria y su reelección sobre los indios: Los derechos del hombre $y$ de los pueblos. Madrid: Edibesa.

INSTITUTO INTERNACIONAL DE DERECHO Y SOCIEDAD (IIDS)

2014 Ayuda Memoria: Comunidad Nativa Tres Islas: Perseguida Por Ejercer Funciones Jurisdiccionales Para Proteger Su Integridad, El Medio Ambiente y Su Futuro. Consulta: 26 de mayo de 2016. Disponible en: $<$ http://www.derechoysociedad.or$\mathrm{g} / 3$-islas/117-caso-tres-islas.html>.

\section{INSTITUTO DE CIENCIAS DA EDU- CACION}

2007 Educación en valores, interculturalismo y convivencia pacífica. Santiago de Compostela: Universidade, Servizo de Publicacións e Intercambio Científico.

KYMLICKA, Will

1996 Ciudadanía multicultural: una teoría de los derechos de las minorías. Barcelona: Paidós.

KINCHELOE, Joe; STEINBERG, Shirley 1999 Repensar el Multiculturalismo. Barcelona: Ediciones Octaedro.

LEDERACH, John Paul

1984 Educar para la Paz. Barcelona: Fontamara.

\section{LLEVOT CALVET, Núria}

2006 La educación intercultural: discursos y prácticas. Catalunya: Edición de la Universidad de Lleida.

\section{MARTINEZ DE BRINGAS, Asier}

2003 Los pueblos indígenas y el discurso de los derechos. Bilbao: Universidad de Deusto. pp. 11-13.

MOLINA LUQUE, Fidel

2008 Alternativas en educación intercultural. El caso de América Latina: la educación intercultural y bilingüe. Centre de Cooperación Internacional de la Universitat de Lleida-España: De País ediciones.

MUÑOZ, Francisco; MOLINA, Beatriz

2010 Una Cultura de Paz compleja y conflictiva. La búsqueda de equilibrios dinámicos. Revista Paz y Conflictos, número 3.

ORGANIZACIÓN INTERNACIONAL DEL TRABAJO

2007 Convenio $N^{\circ} 169$ Sobre Pueblos Indígenas y Tribales en Países Independientes. 2a. ed. Lima: OIT, Oficina Regional para América Latina y el Caribe. Consulta: 26 de mayo de 2016. Disponible en: <http:// www.oit.org.pe/WDMS/bib/publ/ libros/convenio_169_07.pdf>.

PARÍS ALBERT, Sonia; MARTÍNEZ GUZMÁN, Vicent

2004 Interculturalidad y conflicto. Una perspectiva desde la filosofía de la paz. Cátedra Unesco Filosofía Paz / Universitat Jaume I. Consulta: 26 de mayo de 2016. Disponible en: <http://www.justiciaviva.org.pe/derecho_consulta/otros/14.pdf>.

RODRÍGUEZ, José Carlos

2012 Por una cultura de paz: Resolución de Conflictos y mediación. Madrid: Editorial PPC. 
SORIANO AYALA, Encarnación.

2001 Identidad cultural y ciudadania intercultural: su contexto socio educativo. Madrid: La Muralla.

TAYLOR, Charles

1993 El multiculturalismo y la politica del reconocimiento. México: Fondo de Cultura de México. Colección Popular.
TRIBUNAL CONSTITUCIONAL DEL PERÚ

2012 EXPEDIENTE $\mathrm{N}^{\circ}$ 1126-2011HC/TC. Sentencia: 11 de Setiembre de 2012. Consulta: 24 de febrero de 2014. Disponible en: $<$ http://www.tc.gob.pe/jurisprudencia/2012/01126-2011-HC.pdf>.

VIDAL-BENEYTO, José

2004 Derechos Humanos y diversidad cultural: Globalización de las culturas y derechos humanos. Barcelona: Icaria Editorial. 